\title{
Omuz artroskopik cerrahi sonrası kanıta dayalı fizyoterapi ve rehabilitasyon
}

\section{Evidence-based physiotherapy and rehabilitation after arthroscopic shoulder surgery}

\author{
Defne Kaya ${ }^{1}$, Mahmut Nedim Doral ${ }^{1,2}$ \\ ${ }^{1}$ Hacettepe Üniversitesi Tıp Fakültesi, Spor Hekimliği Anabilim Dalı, Ankara \\ ${ }^{2}$ Hacettepe Üniversitesi Tıp Fakültesi, Ortopedi ve Travmatoloji Anabilim Dalı, Ankara
}

\begin{abstract}
Son yıllarda doku iyileşme kalitesinin artmasını sağlayan çok sayıda cerrahi teknik ve dikiş materyallerinin gelişmesi ile birlikte rehabilitasyon programları da daha erken, daha yoğun ve daha hızlı yürütülebilmektedir. Literatür incelendiğinde omuz artroskopik cerrahi sonrası çok sayıda ve farklı içerikleri olan rehabilitasyon programı göze çarpmaktadır. Uygulanması gereken rehabilitasyon programının temel prensipleri, glenohumeral eklem stabilitesinin sağlanması, omuz kuşağı kasların kuvvet stabilizasyonunun sağlanması, skapulohumeral ritmin senkronizasyonu ve propriyoseptif mekanizmanın restorasyonudur. Başta problemin tipi ve uygulanan cerrahi yöntem olmak üzere, cerrahi sonrası rehabilitasyon programı hastaya özgün ve yapılan tekniğe uygun olmalıdır. Her program hastanın yaşı, aktivite düzeyi, tedaviye katılımı, hedefleri ve yaptığı spor tipi göz önünde bulundurularak şekillendirilmelidir.
\end{abstract}

Anahtar sözcükler: fizik tedavi modaliteleri; rehabilitasyon; artroskopik cerrahi; manşon, rotator; omuz çıkı̆̆ı; eklem instabilitesi
In recent years, it is possible to carry out the rehabilitation programs much earlier, more intensively, and quickly with the development of various surgical techniques and a large number of suture material which has increased the quality of tissue healing. In the literature, a large number of shoulder arthroscopic surgery and rehabilitation program with different contents are outstanding. The basic principles of the rehabilitation program to be implemented are: ensuring the stability of the glenohumeral joint of the shoulder, providing stabilization force of the muscles of shoulder girdle, synchronization of the scapulohumeral rhythm, and restoration of the proprioceptive mechanism. Taking into consideration the type of problem and the surgical implementations, the patient rehabilitation program after surgery must be original and appropriate to the applied technique. Each program must be shaped taking into account the patient's age, activity level, participation in the treatment, the objectives and type of sports he/she is practicing.

Key words: physical therapy modalities; rehabilitation; arthroscopic surgery; rotator cuff; shoulder dislocation; joint instability

kinematiğinde değişimler ve omuz kuşağı kaslarında zayıflıkla sonuçlanır. ${ }^{[1]}$ Semptomatik rotator manşet yırtıkları, yaşla artmakla birlikte, genel popülasyonun \%4 ilâ \%32'sinde görülmektedir. ${ }^{[2]}$ Tam kat ya da tama yakın kısmi yırtıkların açık ve kapalı teknik seçenekleri, ağrıyı azaltma ve fonksiyonelliği değerlendiren ölçütlerin etkisinde geliştirilmiştir. ${ }^{[3,4]}$ Cerrahi tekniğe uygun rehabilitasyon programları da, fizyoterapistlerin kişisel deneyimlerine ve cerrahla işbirliğine bağlı olarak, geleneksel yaklaşımdan, hızlandırılmış veya hızlı yaklaşıma kadar geniş bir yelpazede uygulanmaktadır. ${ }^{\left[{ }^{[}\right]}$

Histolojik çalışmalar, cerrahi sonrası rotator manşet iyileşmesinin, inflamatuar-tamir-yeniden şekillenme olmak üzere üç fazda gerçekleştiğini göstermiştir. [6] Cerrahi olarak manşetin kemiğe fiksasyonu sonrası inflamatuar hücreler, trombositler ve fibroblastları

Rotator manşet sorunları sıklıkla ağrı ile kendini gösterir, omuz ekleminde instabilite, glenohumeral

- Illetişim adresi: Prof. Dr. Mahmut Nedim Doral, Büklüm Sk. No:72 Kavaklıdere, Ankara

Tel: 0312 - 4663838 e-posta: mndoral@gmail.com

- Gelis tarihi: 24 Temmuz 2013 Kabul tarihi: 25 Ekim 2013 
izleyerek tamir bölgesine ilerler, 2-3 hafta içinde çoğalmaya başlar. Tamir, cerrahi sonrası üç-dört hafta içinde başlamasına rağmen, tamir bölgesinin tepe tensil kuvvetine ulaşması, cerrahi sonrası 12-16 haftadan önce gerçekleşmez. ${ }^{[6,7]}$

\section{Genel yaklaşımlar}

\section{Immobilizasyon}

İmmobilizasyon, ister açık isterse kapalı teknikle yapılsın, rotator manşet cerrahisi sonrası en sık görülen artsorundur. ${ }^{[8]}$ Hayvan çalışmaları, immobilizasyonun erken dönem harekete kıyasla, tamir bölgesindeki gerimi en aza indirdiğini, kollajen dizilimini ve visko-elastik özellikleri geliştirdiğini göstermiştir. ${ }^{[9]}$ Cerrahiyi korumak amacıyla immobilizasyonun sağlanması, eklem sertliğinin gelişmesine neden olur. Bu riski ortadan kaldırmak için, erken dönem başlanacak pasif eklem mobilizasyonu uygulanmalıdır. Pasif hareketin, eklem hareket sınırını azaltan ve eklem sertliğine yol açan subakromial aralıktaki skar doku oluşumunu azalttığı gösterilmiştir. ${ }^{[10]}$ Kolun pozisyonu da tendonun erken iyileşme sürecinde diğer önemli bir etkendir. Kanıta dayalı çalışmalar, hafif abduksiyon pozisyonunda 4-6 hafta boyunca immobilizasyonun, tendonun dolaşımını arttırdığını ve tamir bölgesinde en düşük tensil kuvveti oluşturduğunu göstermiştir. ${ }^{[11]}$

\section{Kryoterapi}

Kryoterapi, cerrahi sonrası ağrı, şişlik, kas spazmı azaltmak ve inflamatuar yanıtı kontrol altına almak için kullanılır. Kryoterapi cerrahi sonrası 10 ilâ 14 gün arasında kullanılması önerilmektedir. ${ }^{[12]}$

\section{Rehabilitasyon programı}

Hangi teknik ve hangi rehabilitasyon programı uygulanırsa uygulansın, hastaya özgü ve uyabileceği programa, cerrahın öneri ve istekleri ile fizyoterapistin klinik deneyimleri son şekli vermelidir.

Geleneksel rehabilitasyon programları, tendon üzerinde oluşabilecek gerimi azaltmak/kontrol etmek için erken pasif hareketi kısıtlamaktadır. Daha güncel programlarda ise, hastanın ağrı seviyesine bağlı olmakla birlikte, daha birinci günden pasif hareket önerilmektedir.

\section{Faz I}

Bu fazın önemli amacı, tendonu korumak ve üzerine binecek stresleri en aza indirmektir. Bu amaç bazen, tendonu iyileşme sürecinde korumak ile cerrahi sonrası yapışılık oluşumu arasında ciddi bir ikilem yaratır. Tamir bölgesinde kollajen depolanması ve büyüme faktörlerindeki artış, cerrahi sonrası onuncu günde en üst seviyeye, 28 ilâ 56 günde ise bir platoya erişir. ${ }^{[7]}$ Yeni kırılgan kollajen doku, aktif hareketin oluşturacağı tensil kuvvetini kaldıramasa da, fibrillerin düzgün dizilimini ve iyileşmesini sağlamak için nazik pasif harekete ihtiyaç duyar. Günümüzde hem geleneksel hem de güncel programlar, eklem hareket sertliğini en aza indirmek için, erken dönemde ağrısız eklem hareket sınırlarında, pasif hareket ve pasif eklem mobilizasyonu önermektedir. ${ }^{[13]}$ Faz l'de, nötral rotasyonda askı kullanımı önerilebilir. Dirsek, el bileği ve servikal bölge için ise postüral eğitim egzersizleri verilebilir. Nötral pozisyondan başlanılan, izole skapular depresyon ve protraksiyon egzersizleri minimal posterior rotator manşet aktivitesini sağlar. "Skapular saat" ve skapular retraksiyon egzersizlerinin, supraspinatus kasında güvenli olmayan seviyelerde kontraksiyon kurveti oluşturduğu gösterilmiştir. ${ }^{[14]}$ Pendulum (Codman) egzersizleri bu fazda 20 $\mathrm{cm}$ çapında küçük konsantrik daireler çizerek yapılmalıdır. $\mathrm{Bu}$, supraspinatus ve infraspinatus kaslarındaki maksimal istemli kontraksiyonun \%15'inden daha az stres oluşturur. ${ }^{[14]}$ Faz l'den Faz I'ye geçiş ölçütleri: 1) En az $125^{\circ}$ pasif fleksiyon, 2) Skapular planda en az $75^{\circ}$ dış rotasyon, 3) Skapular planda en az $75^{\circ}$ iç rotasyon ve 4) Skapular planda en az $90^{\circ}$ glenohumeral abduksiyonun başarılmış olmasıdır.

\section{Faz II}

$\mathrm{Bu}$ faz, ağrısız pasif eklem hareketi kazanıldığında ve aktif yardımlı harekete izin verildiğinde başlamış olur. Hastanın yaşına, tamirin genişliğine bağlı olmakla birlikte, bu faz cerrahi sonrası 4-8 hafta kadar sürer. İnflamatuar fazdan tamir fazına geçilmiş, hatta tamirden yeniden şekillenme fazına dönülmüştür. Aktif yardımlı ve yavaş aktif egzersizler, kollajen liflerinin düzgün dizilimini uyaracak tensil kuvvetini oluştururlar. ${ }^{[7]} \mathrm{Bu}$ fazda, sırtüstü pozisyonda, diğer elin ya da bir bastonun yardımıyla gerçekleştirilecek aktif glenohumeral iç ve dış rotasyon egzersizleri ile duvarda topla yapılacak kaydırma egzersizleri önerilmelidir. Omuz kuşağı kaslarının kontrolünün sağlanmasının, rotator manşet tamirleri sonrası eksiksiz fonksiyon için önemli bir ölçüt olduğu unutulmamalıdır. Skapular depresyon ve retraksiyon egzersizleri ile üst trapezin aktivitesi baskılanırken, serratus anteriorun eğitimi için $90^{\circ}$ 'den $120^{\circ}$ 'ye ilerleyen glenohumeral fleksiyonda skapular protraksiyon çalıştırılmalıdır. Ekstremite üzerine ağılık verilmeden "bench-press" egzersizine, sırtüstü pozisyondan oturur pozisyona ilerlenerek bu fazda başlanılmalıdır. Yan yatışta dış rotasyon egzersizleri, yüksek infraspinatus ve teres minor aktivitesi ile gerçekleştirilen, skapular stabilizasyon egzersizleri ile birlikte önerilmelidir. ${ }^{[15]}$ Yine bu fazın sonlarını, "selam verme", supraspinatusun en çok aktive olduğu "full can", submaksimal seviyede 
izometrik iç-dış rotasyon egzersizleri ile propriyoseptif egzersizler oluşturur. Faz II'den Faz III'e geçiş ölçütleri: 1) Tam aktif hareketin sağlanması ve 2) Skapular diskinezi işaretlerinin bulunmamasıdır. Günlük yaşam aktivitelerini ağrısız gerçekleştiren ve kuvvetlendirme egzersizlerini ağrısız tamamlayan hastalar Faz IV için adaydır.

\section{Faz III-IV}

Cerrahi sonrası 8-12 haftalarda başlayan Faz III ve 12-16 haftalarda kurvetlendirmenin şiddeti artırılmış şekilde Faz IV, tamamen rotator manşet kaslarını kuvvetlendirme egzersizlerini içerir. Elastik bantlar, ağırlıklar, istasyonlar kullanılacağı gibi, "core stabilizasyon" egzersizleri, açık ve kapalı kinetik zincir egzersizleri ile dirençli propriyoseptif nöromusküler fasilitasyon ve ritmik stabilizasyon teknikleri, kullanılarak hem dinamik hem de statik stabilizasyon geliştirilmesi hedeflenmelidir. ${ }^{[16]}$ Özellikle Faz IV, plyometrik egzersizleri, özgürlük anıtı pozisyonunda kuvvetlendirme egzersizleri, fırlatma egzersizleri, ağılık aktarma pozisyonunda "push-up" egzersizleri ile spora dönüş fazına hazırlık için temel oluşturur. ${ }^{[16]}$

\section{Spora dönüş}

Her iki ekstremite karşılaştırıldı̆̆ında, simetrik hareket ve kuvvet, normal skapulotorasik kinematik gelişmişse, dinlenme ve aktivite sırasında ağrı hissedilmiyorsa, hasta spora dönebilir. Spora özgü çalışmaların temelini kardiyovasküler dayanıklıık ve esnekliğin geliştirilmesi ile birlikte rotator manşet, skapulotorasik, alt ekstremite ve "core stabilizasyon" kuvvetlendirme oluşturmalıdır. ${ }^{[16]}$

\section{ARTROSKOPIK ANTERIOR STABILIZASYON CERRAHISI SONRASI FIZYOTERAPI VE REHABILITASYON}

Basit olarak artroskopik Bankart tamiri, stabil olmayan labrumun glenoid kaviteye dikilmesiyle omuz stabilitesini yeniden sağlayan cerrahi teknik olarak tanımlanabilir.[17] Günümüzde sıklıkla, Bankart tamiri ile birlikte eklem kapsül plikasyonu da yapılmaktadır. ${ }^{[18]}$ Bu cerrahilerin artroskopik doğasına bağlı olarak rotator manşet genellikle etkilenmediği için, aktif normal eklem hareketi, stabilite ve kurvetlendirme egzersizlerinde korunmak durumunda değildir. Bununla birlikte, kapsül, ligament ve labrumun, dokunun düzgün iyileşmesini sağlanmak ayrıca dikiş ve çapaların korunması için en az altı hafta dikkatli olunması, az ve uygun stres altında bırakılması gerekmektedir. ${ }^{[19]}$ Uygulanan rehabilitasyon programı, lezyona, doku kalitesine, fiksasyon yöntemine ve pozisyonuna göre değişir. İyileşmenin düzgün olması için, cerrahi sonrası erken dönemde, eklem hareket ve kuvvetlendirme egzersizleri yavaş yavaş arttırılmalıdır.

\section{Rehabilitasyon prensipleri}

Eskiden artroskopik instabilite cerrahisi sonrası iki ilâ dört hafta immobilizasyon önerilirken ${ }^{[20]}$, günümüzde erken normal eklem hareketinin güvenli olduğu ve fonksiyonel seviyeye erken dönüş ile tam eklem hareketinin kazanılması bakış açısını değiştirmiştir. ${ }^{[21] ~ I ̇ m m o b i l i z a s y o n ~ s u ̈ r e s i, ~ h a s t a n ı n ~ d u r u m u-~}$ na, patolojiye, eklem laksitesine, geçmiş cerrahi öyküsüne, cerrahi tekniğe ve tercihine göre $0-4$ hafta arasında değişebilir.

Pasif ve aktif-yardımlı normal eklem hareketinin kazanılma hızının dengesi (çok hızlı ya da çok yavaş) cerrahi bölgeyi korumak kadar önemlidir. Özellikle dış rotasyon olmak üzere eklem hareketinin çok hızlı geri kazanılmasının tekrarlayan laksiteye, çok yavaş kazanılmasının da inatçı eklem sertliğine yol açabileceği unutulmamalıdır. Cerrahi tamirin korunmasında ilk altı hafta çok önemlidir. İlk altı haftalık süreçte eklem hareketinin son sınırlarında yapılacak germelerden, özellikle de omuz kapsülünün antero-inferiorunda tensil kuvvet oluşturduğu için, kaçınılması gerekir. Aynı zamanda hastaya, ağırlık taşımaması ve eklem hareketinin son noktalarına kadar kolunu kaldırmaması gerektiği mutlaka anlatılmalıdır. Cerrahi sonrası ilk dokuz haftalık güvenli hareket sınırları Tablo 1'de gösterilmiştir.[22]

Tablo 1. Artroskopik omuz instabilite cerrahisi sonrası güvenli hareket sınırları ${ }^{[22]}$

\begin{tabular}{lcccc}
\hline & Pasif fleksiyon & $\begin{array}{c}20^{\circ} \text { abduksiyonda pasif } \\
\text { diş rotasyon }\end{array}$ & $\begin{array}{c}90^{\circ} \text { abduksiyonda pasif } \\
\text { dış rotasyon }\end{array}$ & Aktif fleksiyon \\
\hline 3. hafta & $90^{\circ}$ & $10-30^{\circ}$ & Yapılmamalı! & Yapılmamalı! \\
6. hafta & $135^{\circ}$ & $35-50^{\circ}$ & $45^{\circ}$ & $115^{\circ}$ \\
9. hafta & $135^{\circ}$ & $50-65^{\circ}$ & $75^{\circ}$ & $145^{\circ}$
\end{tabular}




\section{Rehabilitasyon programı}

Faz I (1-6 hafta)

Glenohumeral eklem, standart omuz askısı yardımıyla, iç rotasyon ve adduksiyonda 0-4 hafta immobilize edilmelidir. Hastanın eğitimi bu faz için çok önemlidir. Cerrahi teknik nedeniyle, kapsülün antero-inferior bölgesinde tensil kuvveti oluşturacak abduksiyon/dış rotasyon hareketinin bu fazda yapılmaması, normal eklem hareket sınırının çok hızlı kazanılmaması, omuz askısının doğru kullanılması (kolu iç rotasyon ve adduksiyonda tutması) ve günlük yaşam hareketlerinde kolu kısıtlı olarak kullanması gerektiği hastaya mutlaka anlatılmalıdır. Mutlak immobilizasyonu takiben: Pendulum (Codman) egzersizleri (ağırlık kullanılmadan), skapular planda pasif/aktif-yardımlı fleksiyon egzersizleri, kol destekli ve hafif abduksiyonda $\left(20^{\circ}\right)$ iken pasif/aktif-yardımlı dış rotasyon egzersizlerine başlanabilir. Eğer hasta tolere edebiliyorsa, "skapular saat" veya alternatif olarak elevasyon-protraksiyonretraksiyon egzersizlerinden skapular kuvvetlendirmeye doğru ilerlenebilir. ${ }^{[23]}$ Yine bu fazda, submaksimal rotator manşet izometrik egzersizleri ile postüral farkındalık eğitimlerine geçilebilir. Faz l'den Faz Il'ye geçiş ölçütleri: 1) Uygun iyileşme sürecinin devam etmesi, 2) Belirlenen normal eklem hareket sınırının kazanılması ve 3) İnflamasyonun kontrol altında (ağrısız eklem hareketinin kazanılması) olmasıdır.

\section{Faz II (6-12 hafta)}

Tüm yönlerde ve belirlenen sınırlar içinde, pasif/ aktif-yardımlı normal eklem hareketinin kazanılması da bu fazın yoğunlaşılması gereken ölçütlerindendir. $\mathrm{Bu}$ faz, daha sıklıkla skapular ve rotator manşet kaslarının nöromusküler eğitimini içerir: Skapular retraktör ve yukarı doğru rotatörlerinin kuvvetlendirilmesi, gergin pektoralis minor esnekliğinin el ile germe veya havlu ile mobilizasyonun sağlanması, "push-up" yapmadan eller ve ayaklar üzerinde skapular protraksiyon egzersizlerinin yapılması, "core stabilizasyon" egzersizleri ve propriyoseptif nöromusküler fasilitasyon tekniklerinin kullanılması önerilmektedir. Rotator manşet, skapular ve gövde kaslarının, ağrı oluşturmamak ve düşük stres oluşturmak şartıyla, ağırlık, el ile direnç ve "core stabilizasyon" egzersizleri ile kuvvetlendirilmesi, iyi ve dengeli bir rotator manşet kuvvetinin humeral başı glenoid kaviteye düzgün yerleşimi açısından kritiktir. Skapular planda $45^{\circ}$ 'den az elevasyon pozisyonunda, elastik bant ya da ağırlıklar kullanılarak iç rotasyon, dış rotasyon ve fleksiyon egzersizleri bu fazda başlanabilir. Aktif yardımlı egzersizlerden aktif ve dirençli egzersizlere geçilmelidir. Kuvvetlendirme egzersizleri, dirsek seviyesinde başlayıp önce omuz seviyesine sonra da baş üstü seviyeye ilerlemelidir. Bu fazın sonlarına doğru, kol " $90^{\circ}-90^{\circ}$ ” pozisyonunda, dış rotasyon çalışılmalıdır. Rotator manşet ve skapular stabilizasyon kuvvetlendirme egzersizlerine fazla tekrar (30-50 tekrar) ve düşük ağırlıkla $(0,5-1,5 \mathrm{~kg})$ başlanmalıdır. Hasta 12 hafta boyunca asla ağır kaldırmamalı ve plyometrik egzersizlerine asla başlanmamalıdır. ${ }^{[22,23]}$ Faz II'den Faz III'e geçiş ölçütleri: 1) Aktif normal eklem hareketinin ağrısız başarılması ve 2) Normal eklem hareketi ve kuvvetlendirme egzersizleri sırasında dinamik, dinlenme sırasında ise postüral skapular kontrolün gelişmiş olmasıdır.

Faz III (12-24 hafta)

$\mathrm{Bu}$ faz, ağır kaldırma, tekrarlı hareketler ve baş üstü spor gibi birçok aktivitenin serbest bırakıldığı ve günlük yaşama, işe ve spora tam dönüşün sağlandığı dönemdir. Eklem hareket kısıtlılığı için aktif germeler, eklem mobilizasyonları bu fazda uygulanabilir. Deltoid, latissimus dorsi ve pektoralis major gibi üst ekstremitenin birincil kaslarına yönelik ilerleyici ağırlık kaldırma egzersizlerine başlanmalıdır. Düşük ağırlık ve fazla tekrar (15-25 tekrar/set) ile başlanıp, aylar içinde ağırlık arttırılıp tekrar sayısı azaltılmalıdır. İzotonik "press" (omuz seviyesinden baş üstü seviyeye ilerlenmeli), "row-skapular retraksiyon", "Hughston", plyometrikler gibi bu faz için tanımlanmış özel egzersizler hastayı spora hazırlamak için programa dahil edilmelidir. Plyometrik egzersizler, haftada birkaç kez (15-20 tekrar/set, 3-5 set/gün) yüksek hız ve çoklu skapular planda en az üç hafta yapıldıktan sonra fonksiyonel plyometrik egzersizlere geçiş yapılmalıdır. ${ }^{[22,23]}$

\section{Spora dönüş}

Cerrahiden en az 16 hafta sonra, firlatma, yüzme ve golf gibi sporlara kontrollü olarak geçiş izni verilebilir. Bu karar için, ağrısız normal eklem hareketinin tam olması, kas kuvvet ve dengesinin, dayanıklılığının geliş̧miş olması ölçütttür. ${ }^{[22,23]}$

Artroskopik omuz cerrahileri sonrası uygulanan rehabilitasyon programının etkinliği ve başarısını belirleyen temel etkenler, instabilitenin tipi (doğuştan veya edinilmiş), hastanın cerrahiye yanıtı, ek cerrahi girişimin olup olmadığı, hasta eğitimi ve rehabilitasyon programının dereceli olarak cerrah ve fizyoterapist arasındaki ortak karar ile doğru zamanda ilerletilmesidir.

Başta problemin tipi ve uygulanan cerrahi yöntem olmak üzere, cerrahi sonrası rehabilitasyon programı hastaya özgün ve yapılan tekniğe uygun olmalıdır. Her program hastanın yaşı, aktivite düzeyi, tedaviye katılımı, hedefleri ve yaptığı spor tipi göz önünde bulundurularak şekillendirilmelidir. 


\section{KAYNAKLAR}

1. Lin JC, Weintraub N, Aragaki DR. Nonsurgical treatment for rotator cuff injury in the elderly. J Am Med Dir Assoc 2008;9(9):626-32. CrossRef

2. Boykin RE, Heuer HJD, Vaishnav S, Millett PJ. Rotator cuff disease -basics of diagnosis and treatment. Rheumatology Reports 2010;2(e1):1-12. CrossRef

3. Bennett WF. Arthroscopic repair of massive rotator cuff tears: a prospective cohort with 2- to 4-year follow-up. Arthroscopy 2003;19(4):380-90.

4. Budoff JE, Nirschl RP, Guidi EJ. Débridement of partialthickness tears of the rotator cuff without acromioplasty. Long-term follow-up and review of the literature. J Bone Joint Surg Am 1998;80(5):733-48.

5. Noyes FR, DeMaio M, Mangine RE. Evaluation based protocols: a new approach to rehabilitation. Orthopedics 1991;14(12):1383-5.

6. Gulotta LV, Rodeo SA. Growth factors for rotator cuff repair. Clin Sports Med 2009;28(1):13-23. CrossRef

7. Carpenter JE, Thomopoulos S, Flanagan CL, DeBano CM, Soslowsky LJ. Rotator cuff defect healing: a biomechanical and histologic analysis in an animal model. J Shoulder Elbow Surg 1998;7(6):599-605.

8. Tauro JC. Stiffness and rotator cuff tears: incidence, arthroscopic findings, and treatment results. Arthroscopy 2006;22(6):581-6.

9. Thomopoulos S, Williams GR, Soslowsky LJ. Tendon to bone healing: differences in biomechanical, structural, and compositional properties due to a range of activity levels. J Biomech Eng 2003;125(1):106-13.

10. Peltz CD, Dourte LM, Kuntz AF, Sarver JJ, Kim SY, Williams GR, Soslowsky LJ. The effect of postoperative passive motion on rotator cuff healing in a rat model. J Bone Joint Surg Am 2009;91(10):2421-9. CrossRef

11. Rathbun JB, Macnab I. The microvascular pattern of the rotator cuff. J Bone Joint Surg Br 1970;52(3):540-53.

12. Capps SG, M.B. Cryotherapy and Intermittent Pneumatic Compression for Soft Tissue Trauma. Human Kinetics 2009;14(1):2-4.
13. Brislin KJ, Field LD, Savoie FH 3rd. Complications after arthroscopic rotator cuff repair. Arthroscopy 2007;23(2):124-8.

14. Smith J, Dahm DL, Kaufman KR, Boon AJ, Laskowski ER, Kotajarvi BR, Jacofsky DJ. Electromyographic activity in the immobilized shoulder girdle musculature during scapulothoracic exercises. Arch Phys Med Rehabil 2006;87(7):923-7.

15. Long JL, Ruberte Thiele RA, Skendzel JG, Jeon J, Hughes RE, Miller BS, Carpenter JE. Activation of the shoulder musculature during pendulum exercises and light activities. J Orthop Sports Phys Ther 2010;40(4):230-7. CrossRef

16. Uhl TL, Carver TJ, Mattacola CG, Mair SD, Nitz AJ. Shoulder musculature activation during upper extremity weight-bearing exercise. J Orthop Sports Phys Ther 2003;33(3):109-17.

17. Benedetto KP, Glötzer W. Arthroscopic Bankart procedure by suture technique: indications, technique, and results. Arthroscopy 1992;8(1):111-5.

18. Cole BJ, Millett PJ, Romeo AA, Burkhart SS, Andrews JR, Dugas JR, Warner JJ. Arthroscopic treatment of anterior glenohumeral instability: indications and techniques. Instr Course Lect 2004;53:545-58.

19. Roth CA, Bartolozzi AR, Ciccotti MG, Wetzler MJ, Gillespie MJ, Snyder-Mackler L, Santare MH. Failure properties of suture anchors in the glenoid and the effects of cortical thickness. Arthroscopy 1998;14(2):186-91.

20. Kim SH, Ha KI, Cho YB, Ryu BD, Oh I. Arthroscopic anterior stabilization of the shoulder: two to six-year follow-up. J Bone Joint Surg Am 2003;85-A(8):1511-8.

21. Kim SH, Ha KI, Jung MW, Lim MS, Kim YM, Park JH. Accelerated rehabilitation after arthroscopic Bankart repair for selected cases: a prospective randomized clinical study. Arthroscopy 2003;19(7):722-31.

22. Levine WN, Rieger K, McCluskey GM 3rd. Arthroscopic treatment of anterior shoulder instability. Instr Course Lect 2005;54:87-96.

23. Smith J, Dietrich CT, Kotajarvi BR, Kaufman KR. The effect of scapular protraction on isometric shoulder rotation strength in normal subjects. J Shoulder Elbow Surg 2006;15(3):339-43. 